\title{
Pilot-scale recovery of rare earths and scandium from phosphogypsum and uranium leachates
}

\author{
Maxim Mashkovtsev ${ }^{1}$, Maxim Botalov ${ }^{1}$, Denis Smyshlyaev ${ }^{1}$, Risto Pajarre ${ }^{2, a}$, Petteri Kangas ${ }^{2}$, Vladimir \\ Rychkov $^{1}$, and Pertti Koukkari ${ }^{2}$ \\ ${ }^{1}$ Institute of Physics and Technology Ural Federal University, Russia \\ ${ }^{2}$ VTT - Technical Research Centre of Finland
}

\begin{abstract}
Ural Federal University (UrFU) and VTT have performed joint research on development of industrial technologies for the extraction of REM and Scandium compounds from phosphogypsum and Uranium ISL leachate solutions. Leaching-absorption experiments at UrFU have been supported with multicomponent solution modelling by VTT. The simulations have been performed with VTT's ChemSheet/Balas program and can be used for speciation calculations in the lixiviant solution. The experimental work combines solvent extraction with advanced ion exchange methodology in a pilot facility capable of treating $5 \mathrm{~m} 3$ solution per hour. Currently, the plant produces cerium carbonate, lanthanum oxide, neodymium oxide and concentrate of heavy rare earth metals. A batch of $45 \mathrm{t}$ solids has been processed with the gain of $100 \mathrm{~kg}$ 's of REM concentrate. A mini-pilot plant with productivity above 50 liters per hour has been applied to recover scandium oxide and REE concentrates from the uranium ISL solution. As the preliminary product contains radioactivity (mainly strontium), an additional decontamination and cleaning of both concentrates by extraction has rendered a necessity. Finally a purified $99 \%$ concentrate of scandium oxide as well as $99 \%$ rare earth concentrate are received.
\end{abstract}

\section{Introduction}

In the processing or Rare Earth Elements (REE) saline solutions containing large amounts of $\mathrm{Fe}, \mathrm{Al}$ and other elements are typically formed. The extraction of REE and Sc from those is an elaborate task by traditional chemical methods. For example in the industrial scale recovery of REE and Sc from these solutions the traditional method is deposition by ammonia, alkalis and anions such as $\mathrm{F}^{-}, \mathrm{S}_{2} \mathrm{O}_{4}{ }^{2-}$, and $\mathrm{PO}_{4}{ }^{3-}$. Disadvantages then include large loss of REE $(20-25 \%)$ [1, 2] as coprecipitating hydroxides of metals such as $\mathrm{Fe}(\mathrm{III}), \mathrm{Al}, \mathrm{Zr}$ and $\mathrm{Ti}$. In addition, waste waters caused by the large flow rates, chemicals used for precipitation and low regeneration rates are difficult to process.

Sorption and extraction are currently the most promising method for extracting REEs from dilute solutions [2, 3], since they have a high-performance, and a simple hardware design and are selective and well suitable for construction of closed circulation. In this study of concentrating REE and Sc

\footnotetext{
${ }^{a}$ Corresponding author: Risto.Pajarre@vtt.fi
} 
from Uranium ISL solutions, solid ion exchange materials, insoluble to aqueous media were used. The received concentrates were subjected to additional purification to achieve decontaminated products.

\section{Materials and applied methods}

Table 1. Composition of return liquor used in the experiments.

\begin{tabular}{|c|c|c|c|c|c|}
\hline Element & Content, mg/dm & Element & Content, $\mathbf{~ m g / d m}$ & Element & Content, mg/dm \\
\hline Copper & 0.63 & Boron & 24.6 & Dysprosium & 0.93 \\
\hline Zinc & 23 & Barium & 0.044 & Holmium & 0.16 \\
\hline Iron & 692 & Indium & 0.009 & Erbium & 0.46 \\
\hline Calcium & 339 & Ytrium & 4.68 & Thulium & 0.075 \\
\hline Magnesium & 252 & Lanthanum & 2.10 & Ytterbium & 0.51 \\
\hline Aluminium & 111 & Cerium & 9.66 & Lutetium & 0.073 \\
\hline Beryllium & 0.56 & Praseodymium & 1.77 & Hafnium & 0.014 \\
\hline Molybdenum & 0.23 & Neodymium & 6.25 & Scandium & 1.18 \\
\hline Rhenium & 0.005 & Samarium & 1.24 & Thorium & 11.7 \\
\hline Manganese & 15 & Europium & 0.34 & Uranium & 5.7 \\
\hline Cadmium & 0.1 & Gadolinium & 1.03 & & \\
\hline Chromium & 16 & Terbium & 0.13 & & \\
\hline
\end{tabular}

\subsection{Raw materials and research facilities}

Russian uranium ore deposits handled by ISL are located usually in sediments alternating with gravel sands, sandstones and siltstones. The major components of the main ores consist of aluminosilicates (with silica and alumina contents $70-85 \%$ and $3.5-18.5 \%$, respectively) containing practically no carbonates.

Uranium is present as pitchblende (an average of 40-60\%) and coffinite in the intergranular spaces of sandy rocks, sometimes substituting cementitious clay. Uranium minerals tend to have high contents of molybdenum and selenium (up to $0.01-0.2 \%$ ). Content of scandium in permeable lithological precipitate types varies from $4.7 \mathrm{~g} / \mathrm{t}$ to $10.42 \mathrm{~g} / \mathrm{t}$. In average for the permeate side of the section Sc content is $6 \mathrm{~g} / \mathrm{t}$.

The content of the lanthanide varies from $123 \mathrm{~g} / \mathrm{t}$ in the grits to $171-222 \mathrm{~g} / \mathrm{t}$ in the sandstones, reaching maximum values in clay varieties (up to $447 \mathrm{~g} / \mathrm{t}$ ) in the barren rocks of the ore-bearing layers.

Iron is closely connected with sulfur concentration and varies from $0.4 \%$ to $2-2.8 \%$. The content of sulfates is $2-2.5 \%$, with an average of $0.95 \%$.

The study used returnable solutions ISL Uranium Company "Dalur" after sorption of uranium, which are weakly acidic green solutions. All samples were subjected to prolonged settling and decantation for clarity. This was followed by chemical analysis by ICP mass spectrometry and AAS. The contents of the main impurities are shown in Table 1.

The exact composition of the anionic productive solutions was not fixed in the experiments. The average content were as follows: sulfate ion $10-15 \mathrm{~g} / \mathrm{dm}^{3}$; chloride $0,5-1,2 \mathrm{~g} / \mathrm{dm}^{3}$; acidity of $4-5$ (up to 10) $\mathrm{g} / \mathrm{dm}^{3}$; suspended solids up to $27 \mathrm{mg} / \mathrm{dm}^{3}$.

\subsection{Methodology}

The behaviour of metal ions in the process of sorption of uranium from ISL solutions was studied in both in static and dynamic conditions. The experimental setup for static conditions for determination of the static exchange capacity and desorption study included a shaking platform with a circular action. Plastic flasks with crew caps were used varying the weight ratios of ion exchanger and ISL uranium solution. 
The limiting step during adsorption/desorption is a chemical complex compound formation between the functional group and a rare earth or Sc ion. From previous experience on sorption of rareearth elements in various ion exchangers it was deduced that 36 hours contact time is required and consequently was also adopted in this study.

After completion of the experiment the ion exchanger was separated from the mother liquor using a ceramic sieve. Calculation of the static exchange capacity and the degree of adsorption or desorption was carried out based on the difference in the concentrations of REE / Sc in solution before and after the experiment and the results of desorption. Reproducibility of results was within $5 \%$. All static tests used completely dry resins in $\mathrm{H}^{+} / \mathrm{NH}^{4+}$-forms.

Static equilibrium exchange capacity for REE/Sc of the dry resin, calculated on the residual content of REE/Sc solution is defined by the formula (1):

$$
E_{S T A T}=\left(C_{1}-C_{2}\right) \frac{V_{p}}{m_{c}}
$$

where $C_{1}$ is concentration of REE/Sc in the initial solution $\left(\mathrm{g} / \mathrm{dm}^{3}\right), V p$ volume of the solution taken for tests $\mathrm{dm}^{3}, C_{2}$ concentration of REE/Sc in solution after sorption, $m c$ dry sample weight in the resin $\mathrm{H}^{+} / \mathrm{NH}_{4}{ }^{+}$form. To study the dynamics of the process, the dry ion exchanger $\left(\mathrm{H}^{+} / \mathrm{NH}_{4}{ }^{+}\right.$form $)$was soaked in distilled water and then placed in a glass column with a diameter of $8 \mathrm{~mm}$. The test solution was passed through the resin bed until equal composition at the inlet and outlet of the column was reached. Under controlled flow rate, the eluate fractions were selected for analysis. The flow rate in the sorption and desorption experiments was set using a peristaltic pump. The volume of the resin in the dynamic tests was approximately $10 \mathrm{~cm}^{3}$.

Full dynamic exchange capacity of the dry resin for REM/Sc, calculated on the desorption results is determined by the formula (2):

$$
E_{D Y N}=\frac{C V_{p} V_{\text {res }}}{V_{\text {ionic }}}
$$

where:

$C$-REE/Sc concentration of the stripping solution, $\mathrm{mg} / \mathrm{cm}^{3}$

$V_{p}$-Volume of desorption solution $\mathrm{cm}^{3}$

$V_{\text {ionic }}$-Volume of the resin taken for tests

$V_{\text {res }}$-Specific volume of the resin, $\mathrm{cm}^{3} / \mathrm{g}$.

To study the effect of temperature on the static exchange capacity, the reaction mixture in a glass beaker was placed in an incubator. Stirring was performed with an overhead stirrer.

The effect of the temperature on the dynamic exchange capacity was studied with a ion exchanger column placed in a thermostat. The level of liquid was set to completely cover the resin. Moreover, elution solution of the same temperature was fed into the column using a peristaltic pump.

The degree of desorption was determined by the difference between the REE content of the ion exchanger at saturation and after desorption. The REE content was determined by dissolving the resin in boiling nitric acid and analysing the resulting solution.

The study of the influence of various parameters (acidity, solid-to-liquid ratio) on the deposition of $\mathrm{REE} / \mathrm{Sc}$ concentrates was performed in beaker mixed by an overhead stirrer equipped with a $\mathrm{pH}-$ meter.

Precipitation of REE/Sc concentrates was conducted in an Atlas Calorimeter (Syrris). A liquid circulation thermostat was used keep temperature steady during the exothermic and endothermic reactions. The correct $\mathrm{pH}$ level was automatically maintained, while the acid consumption was recorded by the gravimetric and volumetric methods. 


\section{Results}

\subsection{Sorption of REE from the leaching solutions}

Based on the earlier studies [4-6], it was found that the highly crosslinked sulfonated resins adsorb poorly polymeric ions ( $\mathrm{Zr}, \mathrm{Fe}$ (III), etc.), mainly due to the sieve effect. These differences in the absorption and elution properties of different hydrocomplexes on crosslinked ion exchangers allow for enhanced separation of $\mathrm{Zr}, \mathrm{Fe}, \mathrm{Al}$, Th, and REE ions without adding special complexing agents.

Cations of the same charge those with smaller ionic radii are more prone to hydration and, consequently, have a greater influence on the selectivity with on strong acid cation exchangers. There are comprehensive reviews on the structure of the aqueous ions using the methods of neutron and Xray diffraction $[7-8]$.

To study the sorption of the REE from ISL uranium solutions commercially available sulfonated resins with different contents of divinylbenzene (DVB) were used. While the increase of DVB does not change the structure of the copolymer, it increases the density of the globular formation (gel). This also decreases the distance between the globular molecular entities from $30 \AA$ to $10 \AA$ ( $8 \%$ DVB $\rightarrow$ $20 \%$ DVB) in dry cation exchanger.

The increase in volume of the resin gel by water leads to straightening of the polymer chains by, which means that, on average, the distance between the elementary and interglobular formations increase on average of 2-10 times depending on the DVB content.

The specific surface area sorbent polymer, bulk density, total pore volume, pore volume size distribution were determined for the average pore radius. With increasing DVB content $12 \rightarrow 40 \%$ it was found that the specific surface area of the polysorbent increased while the bulk density decreased and the pore volume increased from 1.4 to $2.1 \mathrm{~cm}^{3}$.

Practical application of macroporous sulfonated resins for the separation of ions revealed the following:

- good operational stability with resins containing no more than $20 \%$ of DVB.

- Industrial sulfonated resins can effectively separate due to the sieve effect only ions that can be polymerized in solution (Mo, W, Zr, Ti)

- the copolymerization with DVB does not always ensure a uniform distribution of crosslinks in the polymer network. This leads to the formation of spatial areas in the sorbents difficult for ions to access, which is the reason for the relatively low values of their sorption capacity.



Figure 1. Schematic diagram of the laboratory setup, where 1 reactor feed solutions; 2 stopcock valve; 3 pump; 4 ion-exchange column; 5 reactor precipitator; 6 reactant feed (reservoir); 7 pH meter; 8 filter; 9 vacuum pump.

All the above material suggests the possibility of an effective REE separation from sulfuric acid solutions in macroporous sulfonic resins that are commercially available in the DVB content of more than $12 \%$. For further research the macroporous sulphocationite M-31 was chosen. Research for the 
development of processing parameters was performed in a laboratory setting. Figure 1 gives a schematic diagram of the setup.

In a series of experiments the specific load on the ISL uranium solution in an ion exchange column was investigated. Determining the optimal unit load will further enable the calculation of the optimal size of the ion exchange column for the breakthrough for the given conditions and the degree of extraction of REE.

Macroporous cation exchangers with high internal surface and a large number of pores have a relatively fast sorption kinetics. For the M-31 the optimum load was estimated to be 5 column volumes of solution to unit volume of the cation exchanger per hour.

\subsection{Washing impurities from cation exchangers}

As mentioned previously, the functional groups of strongly acidic cation exchangers strongly bind REE ions in a wide range of concentrations of sulfuric acid. Therefore, it becomes possible to separate the sulfuric acid adsorbed components according to their distribution coefficients.

To investigate this question, experiments were conducted on the washing of the cation exchanger M-31 saturated ISL uranium solution with sulfuric acid of different concentrations. The studies were conducted in static and dynamic mode. The static value for the washing solution: ion exchanger was 5, while washing for 1 hour. For the dynamic study the transmission rates was 2.5 and 5 volumes of the washing solution to 1 volume of M-31 per hour. The results are shown in Table 2.

Table 2. Results from cation exchanger M-31 washing.

\begin{tabular}{|l|r|r|r|r|r|r|r|r|r|}
\cline { 2 - 10 } \multicolumn{1}{c|}{} & $\mathbf{1 0}$ & $\mathbf{2 5}$ & $\mathbf{5 0}$ & $\mathbf{7 5}$ & $\mathbf{1 0 0}$ & $\mathbf{1 2 5}$ & $\mathbf{1 5 0}$ & $\mathbf{2 0 0}$ \\
\cline { 2 - 11 } \multicolumn{1}{c|}{} & \multicolumn{7}{|c|}{ washing, \% } \\
\hline $\mathrm{Al}$ & 9.02 & 24.40 & 42.99 & 56.18 & 60.37 & 73.93 & 77.40 & 91.20 \\
\hline $\mathrm{Ca}$ & 11.85 & 20.28 & 27.28 & 34.95 & 44.85 & 53.92 & 56.17 & 68.31 \\
\hline $\mathrm{Fe}$ & 13.24 & 17.55 & 51.07 & 38.12 & 49.36 & 56.06 & 61.75 & 85.48 \\
\hline $\mathrm{Y}$ & 2.19 & 4.20 & 10.39 & 17.31 & 17.84 & 27.64 & 30.22 & 48.76 \\
\hline $\mathrm{La}$ & 1.82 & 1.81 & 4.52 & 8.16 & 7.65 & 12.87 & 14.16 & 27.45 \\
\hline $\mathrm{Ce}$ & 1.44 & 1.76 & 4.85 & 8.54 & 8.49 & 14.26 & 15.49 & 30.15 \\
\hline $\mathrm{Pr}$ & 1.64 & 1.88 & 5.02 & 8.84 & 9.86 & 16.36 & 17.76 & 34.17 \\
\hline $\mathrm{Nd}$ & 1.53 & 2.05 & 5.32 & 9.52 & 8.84 & 14.68 & 15.76 & 29.56 \\
\hline $\mathrm{Sm}$ & 1.30 & 2.32 & 5.76 & 10.56 & 10.33 & 16.47 & 18.01 & 33.72 \\
\hline $\mathrm{Eu}$ & 9.92 & 9.65 & 14.78 & 20.27 & 10.11 & 18.28 & 17.32 & 30.73 \\
\hline $\mathrm{Dy}$ & 1.29 & 2.23 & 5.92 & 10.56 & 9.86 & 15.74 & 16.88 & 30.88 \\
\hline $\mathrm{Gd}$ & 1.10 & 2.43 & 6.18 & 11.41 & 10.89 & 17.72 & 18.99 & 34.52 \\
\hline $\mathrm{Tb}$ & 1.04 & 2.74 & 7.24 & 13.13 & 14.12 & 21.90 & 23.38 & 40.56 \\
\hline $\mathrm{Ho}$ & 1.41 & 3.58 & 9.12 & 16.42 & 17.05 & 26.51 & 28.28 & 46.87 \\
\hline $\mathrm{Er}$ & 1.48 & 4.08 & 9.69 & 17.56 & 17.30 & 25.90 & 28.23 & 45.58 \\
\hline $\mathrm{Tm}$ & 1.55 & 4.66 & 11.52 & 19.94 & 21.35 & 31.98 & 34.04 & 54.12 \\
\hline $\mathrm{Yb}$ & 1.74 & 4.55 & 11.71 & 19.94 & 20.08 & 30.26 & 32.70 & 50.32 \\
\hline $\mathrm{Lu}$ & 2.41 & 4.74 & 13.07 & 21.52 & 24.07 & 35.01 & 37.94 & 59.27 \\
\hline $\mathrm{Th}$ & 7.09 & 3.95 & 9.42 & 14.39 & 25.19 & 38.39 & 45.26 & 93.08 \\
\hline $\mathrm{U}$ & 32.81 & 39.73 & 60.33 & 75.15 & 73.43 & 81.55 & 80.91 & 88.62 \\
\hline $\mathrm{NREE}$ & 1.65 & 2.28 & 5.82 & 10.21 & 14.89 & 16.20 & 17.53 & 32.38 \\
\hline
\end{tabular}

From the results it is evident that the optimum concentration of sulfuric acid to the washing solution is $75 \mathrm{~g} / \mathrm{dm}^{3}$. This washes away $38 \%$ of the iron, $58 \%$ of aluminum, $35 \%$ of calcium, $14 \%$ of thorium and $75 \%$ of uranium. Improving the washing efficiency by introducing of additional sulfate to the washing solution ions failed because along with the increase in desorption of impurity elements 
also desorption of REE ions was increased. The optimum load on the column during the washing is 5 volumes of solution to 1 volume of the cation exchanger per hour.

\subsection{Desorption of REEs}

Desorption was carried out with a solution of ammonium sulfate. The choice of this reagent was dictated by the fact that further processing of the eluates will involve the use of ammonia and ammonium salts to precipitate concentrates. Furthermore, ammonium ions have a good desorbing capability because of the affinity to cation binding functional groups [9].

In a series of experiments we studied the effect of concentration of ammonium sulfate on the degree of desorption and the transmission rate on prewashed M-31. From the data it was evident that concentrations in the range of $200-400 \mathrm{~g} / \mathrm{dm}^{3}$ ammonium sulfate can be used for desorption equally effectively. Recommended concentration of ammonium sulfate is $\sim 300 \mathrm{~g} / \mathrm{dm}^{3}$.

The presented data show that the change in the feed rate of the desorbing solution has no strong effect on the dynamics of desorption. Recommended feed rate of 5 times $V / V_{B}$ per hour stripping solution.

\subsection{Deposition of the REE concentrate}

Before precipitation of carbonates REE solution concentrate was treated with $10 \% \mathrm{NH}_{4} \mathrm{OH}$. Preneutralization of the excess acidity of ammonia was necessary, firstly, to help reduce the formation of ammonium carbonate salts, and secondly, to precipitate heavy metal hydroxides of $\mathrm{Fe}^{3+}, \mathrm{Al}^{3+}$ and $\mathrm{Th}^{4+}$ simultaneously sorbed with REE. Precipitation led to $\mathrm{pH} 4.5-5$. This interval is characterized by the end of the precipitation of hydroxides of the above metals. At the same time, substantial hydrolysis of REM is not observed. Coprecipitation of REM does not exceed $1 \%$.

Precipitation of REE as carbonates is a well-studied process. The precipitation is performed by use of ammonium carbonate (130-150 g/ $\mathrm{dm}^{3}$ solution), while use of excess precipitant must be considered to avoid undesired hydrolysis of the carbonates (typical for e.g. the yttrium group elements). In Table 3 the average contents (as elements) of the mother solution and the precipitated REE concentrate are given

Table 3. Content of elements in the mother solution and in the REE carbonate concentrate.

\begin{tabular}{|l|c|c|c|c|c|}
\cline { 2 - 6 } \multicolumn{1}{c|}{} & \multicolumn{5}{c|}{ Element } \\
\cline { 2 - 6 } \multicolumn{1}{c|}{} & Fe & Al & Ca & IREM & Th \\
\hline $\mathrm{mg} / \mathrm{dm}^{3}$ (solution) & 17.2 & 2.0 & 319.6 & 11.0 & 0.1 \\
\hline $\mathrm{w}-\%$ (concentrate) & 0.13 & 9.02 & 0.11 & 32.89 & 0.01 \\
\hline
\end{tabular}

\section{Extraction of scandium}

\subsection{Sorption of scandium from the ISL solution}

In the recovery of $\mathrm{Sc}$ from uranium ISL solutions the kinetic characteristics are important for elucidating the mechanism of sorption process. For example, from the kinetic curves the time to reach equilibrium as well as the maximum operating capacity of the resin at given composition and temperature of the solution can be obtained. Knowledge of the limiting stage allows for refining the extraction process conditions of a particular element in the solution for the optimal choice of ion exchange resins. Furthermore, the kinetic parameters are used in the design of the process hardware.

From the experiments it was determined that at least 10 hours of contact of the ion exchanger and solution was required to approach equilibrium. 
Sorption of metal cations strongly depends on their concentration in solution. The nature of the sorption isotherms gives an indication of the selectivity of the selected ions in these conditions. Therefore, it was important to assess the equilibrium sorption process. In figure 2, the achieved equilibrium content of Sc and Th in the ion exchanger ECO-10M by the Russian company AXION as a function of the saturated solution is presented. The bulge on the sorption isotherm confirms the high selectivity of the selected sorbent with respect to scandium ions in sorption from sulphate solutions of complex cation composition. The sorption extraction of scandium is due to the formation of a coordination bond with the phosphonate group of cation exchanger ECO-10M.

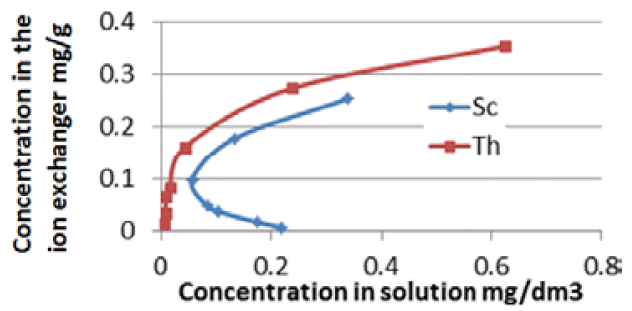

Figure 2. Equilibrium content of Sc and Th in the ECO-10M ion exchanger.

The next series of experiments was conducted in a laboratory setting studying specific load of the ISL uranium solution in an ion exchange column. Determining the optimal unit load allows calculating the optimal size of the ion exchange column for the breakthrough in the given conditions and the degree of extraction of REE.

From the results it was also clear that the increase in the load onto the column by a solution in four times does not affect the capacitive properties cation exchanger. The optimum load is 5 column volumes of solution to 1 volume of the cation exchanger per hour.

\subsection{Washing impurities from the cation exchanger ECO-10M}

Phosphonic functional groups of the cation exchanger ECO-10M firmly hold scandium ions in a wide range of concentrations of sulfuric acid. Therefore, there is the possibility of separating the sulfuric acid adsorbed components according to their distribution coefficients.

To investigate a cation exchanger ECO-10M saturated with ISL uranium solution was washed with sulfuric acid of different concentrations. The studies were conducted in static and dynamic mode.

The optimum concentration of sulfuric acid in the washing solution was found to be $150 \mathrm{~g} / \mathrm{dm}^{3}$. It was found possible to wash away iron ions to $92 \%$ of aluminum ion at $50 \%$ of the calcium ion by $21 \%$, of the thorium ion at $14 \%$ of the uranium ions to $7.6 \%$. The optimum load on the column during the washing is 5 volumes of solution to 1 volume of the cation exchanger per hour.

\subsection{Desorption of scandium}

Some of the REE ions, accompanying elements and thorium series radionuclides are largely adsorbed phosphorus-containing ion exchangers from carbonate solutions [10].

At the same time, the imbibition values of the studied elements are largely dependent on the $\mathrm{pH}$ and the concentration of carbonate ions. Imbibition is lowest for scandium, thorium, and zirconium ions at ion exchangers in high $\mathrm{pH}$ (above 11) and at the solubility limit of alkali metal carbonates and ammonium salts. This allows use concentrated solutions of carbonate ions with high $\mathrm{pH}$ for elution of adsorbed ions from the ion exchanger phase after washing.

In light of [11] data to determine the values of the thermodynamic constants of complex ions of thorium, scandium, zirconium, as well as a list of items included in the initial ISL uranium solutions may choose desorption conditions and a carbonate based precipitation reagent. Knowing the 
thermodynamic properties of the elements enables the separation or concentration of them from the process solutions and avoids formation of deposits in the cation exchanger.

It is known that polynuclear hydrolysis of scandium occurs in weakly acidic solutions, thus resulting hydroxo scandium species. Adding carbonate ions to the solution results in dissolution of scandium (at a ratio of $\mathrm{CO}_{3}^{2-}: \mathrm{Sc}^{3+}=0.75$ ), followed by its complete precipitation in the form of basic carbonate of scandium, which again is completely dissolved when the molar ratio of $\mathrm{CO}_{3}^{2-}: \mathrm{Sc}^{3+}$ is increased to 8.35. Based on the available data of scandium ions in solutions of carbonates the main factor affecting the value of imbibition is the change in charge of complex carbonate ions.

Based on the effectiveness of the stripping scandium cation exchanger ECO-10M carbonate solutions can be arranged in the following order:

$$
\mathrm{NaHCO}_{3}<\mathrm{KHCO}_{3}<\mathrm{K}_{2} \mathrm{CO}_{3}<\left(\mathrm{NH}_{4}\right)_{2} \mathrm{CO}_{3}<\mathrm{NH}_{4} \mathrm{HCO}_{3}<\mathrm{Na}_{2} \mathrm{CO}_{3} .
$$

Studies carried out by stripping under static conditions at a volume ratio solution/cationic ion exchanger $=10$. The most efficient solution was found to be sodium carbonate.

The molar ratio in the solution $\mathrm{CO}_{3}^{2-}: \mathrm{Sc}^{3+}$ determines the composition and the charge of the scandium complex and thus affects the efficiency of desorption. Thus studies were conducted on the degree of desorption as a function of the ratio of the desorption solution: cationic ion exchanger.

The highest efficiency Sc stripping in sodium carbonate solution was found with a concentration of $200 \mathrm{~g} / \mathrm{dm}^{3}$. Desorption of scandium after washing the cation exchanger ECO-10M with sulfate solution should be carried out in a static mode with constant stirring. The optimum ratio of the desorption solution: cation exchanger equals 5 .

The precipitation of scandium concentrate again is a well-known process to be done with an alkaline agent from the desorbed acidified solution ( $\mathrm{pH} 1-2)$. Precipitation $\mathrm{pH}$ for scandium from the concentrate is 5.0-5.5.

\section{REE extraction process model}

A process model of the rare earth elements (REE) fractionation process was developed, see Figure 1. Model is divided in two parts: i) adsorption-desorption where the respective phenomena are modelled based on the reaction equations, and ii) precipitation where the equilibrium chemistry of aqueous water solution is modelled by applying Pitzer model. The applied tools for modelling are Balas [12] for the mass and energy balandes and ChemSheet/ChemApp [13] for the thermodynamic calculations.

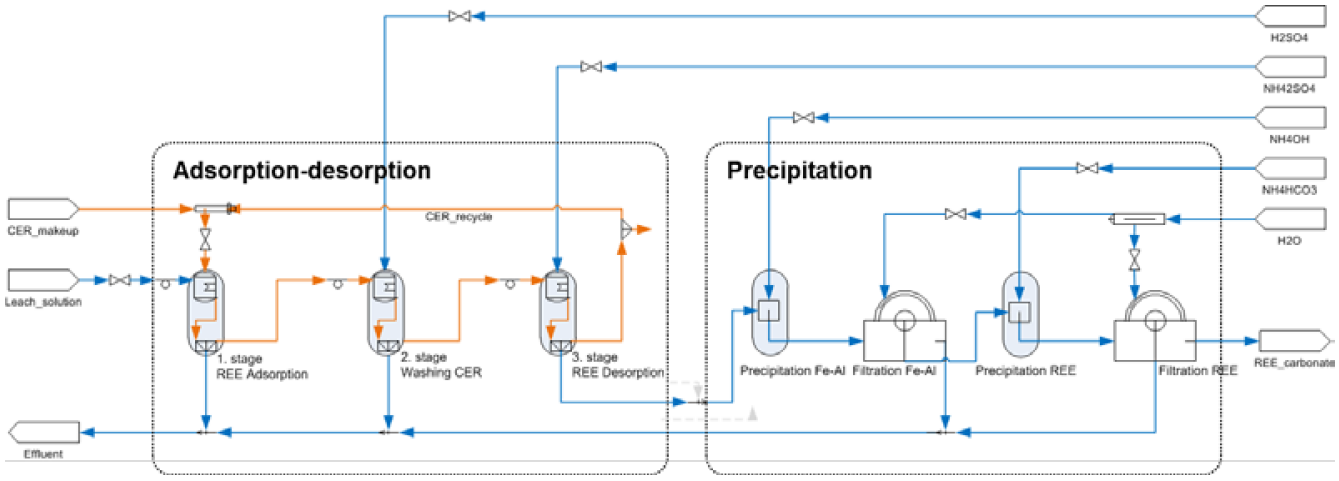

Figure 3. Fractionation of REE from solution. Adsorption-desorption model is based on the reaction equations and Precipitation model is based on the aqueous Pitzer model.

A process model of the rare earth elements (REE) fractionation process was developed, see Figure 1. Model is divided in two parts: i) adsorption-desorption where the respective phenomena are modelled based on the reaction equations, and ii) precipitation where the equilibrium chemistry of 
aqueous water solution is modelled by applying Pitzer model. The applied tools for modelling are Balas [12] for the mass and energy balandes and ChemSheet/ChemApp [13] for the thermodynamic calculations.

As the original chemical systems included multiple rare earth elements and other species a somewhat reduced chemical system is applied for the modelling purposes. Following elements are included as system components: $\mathrm{H}, \mathrm{O}, \mathrm{S}, \mathrm{N}, \mathrm{Ca}, \mathrm{Al}, \mathrm{Fe}, \mathrm{Sc}, \mathrm{La}$ and $\mathrm{Eu}$. Applied constituents are given in Table 4.

Table 4. Applied chemical system for modelling the fractionation of rare earth elements.

\begin{tabular}{|c|c|c|c|c|c|}
\hline Vapour phase & \multicolumn{4}{|l|}{ Aqueous phase } & Pure phases \\
\hline $\begin{array}{l}\mathrm{H}_{2} \mathrm{O}(\mathrm{g}) \\
\mathrm{NH}_{3}(\mathrm{~g})\end{array}$ & $\begin{array}{l}\mathrm{H}(+\mathrm{aq}) \\
\mathrm{Al}(+3 \mathrm{aq}) \\
\mathrm{AlO}(+\mathrm{aq}) \\
\mathrm{AlOH}(+2 \mathrm{aq}) \\
\mathrm{Ca}(+2 \mathrm{aq}) \\
\mathrm{Eu}(+3 \mathrm{aq}) \\
\mathrm{EuO}(+\mathrm{aq}) \\
\mathrm{EuOH}(+2 \mathrm{aq}) \\
\mathrm{EuSO}_{4}(+\mathrm{aq}) \\
\mathrm{Fe}(+3 \mathrm{aq}) \\
\mathrm{Fe}_{2}(\mathrm{OH})_{2}(+4 \mathrm{aq}) \\
\mathrm{Fe}_{3}(\mathrm{OH})_{4}(+5 \mathrm{aq})\end{array}$ & $\begin{array}{l}\mathrm{FeO}(+\mathrm{aq}) \\
\mathrm{FeOH}(+2 \mathrm{aq}) \\
\mathrm{La}(+3 \mathrm{aq}) \\
\mathrm{LaO}(+\mathrm{aq}) \\
\mathrm{LaOH}(+2 \mathrm{aq}) \\
\mathrm{LaSO}_{4}(+\mathrm{aq}) \\
\mathrm{NH}_{4}(+\mathrm{aq}) \\
\mathrm{Sc}(+3 \mathrm{aq}) \\
\mathrm{Sc}\left(\mathrm{SO}_{4}\right)(+\mathrm{aq}) \\
\mathrm{Sc}_{3}(\mathrm{OH})_{5}(+4 \mathrm{aq}) \\
\mathrm{ScO}(+\mathrm{aq}) \\
\mathrm{ScOH}(+2 \mathrm{aq})\end{array}$ & $\begin{array}{l}\mathrm{OH}(-\mathrm{aq}) \\
\mathrm{Al}(\mathrm{OH})_{4}(-\mathrm{aq}) \\
\mathrm{EuO}_{2}(-\mathrm{aq}) \\
\mathrm{FeO}_{2}(-\mathrm{aq}) \\
\mathrm{HSO}_{4}(-\mathrm{aq}) \\
\mathrm{LaO}_{2}(-\mathrm{aq}) \\
\mathrm{Sc}\left(\mathrm{SO}_{4}\right)_{2}(-\mathrm{aq}) \\
\mathrm{Sc}_{2}(\mathrm{OH})_{2}(+4 \mathrm{aq}) \\
\mathrm{ScO}_{2}(-\mathrm{aq}) \\
\mathrm{ScO}_{2} \mathrm{H}(\mathrm{aq}) \\
\mathrm{SO}_{4}(-2 \mathrm{aq})\end{array}$ & $\begin{array}{l}\mathrm{H}_{2} \mathrm{O} \\
\mathrm{AlO}_{2} \mathrm{H}(\mathrm{aq}) \\
\mathrm{CaSO}_{4}(\mathrm{aq}) \\
\mathrm{EuO}_{2} \mathrm{H}(\mathrm{aq}) \\
\mathrm{LaO}_{2} \mathrm{H}(\mathrm{aq}) \\
\mathrm{NH}_{3}(\mathrm{aq}) \\
\mathrm{Sc}_{2}\left(\mathrm{SO}_{4}\right)_{3}(\mathrm{aq})\end{array}$ & $\begin{array}{l}\mathrm{Al}_{2}\left(\mathrm{SO}_{4}\right)_{3} \cdot 6 \mathrm{H}_{2} \mathrm{O} \\
\mathrm{CaSO}_{4} \cdot 2 \mathrm{H}_{2} \mathrm{O} \\
\mathrm{CaSO}_{4} \\
\mathrm{CaSO}_{4} \cdot 0.5 \mathrm{H}_{2} \mathrm{O} \\
\left(\mathrm{NH}_{4}\right)_{2} \mathrm{SO}_{4} \\
\mathrm{Fe}(\mathrm{OH})_{3} \\
\mathrm{Eu}_{2}\left(\mathrm{SO}_{4}\right)_{3} \cdot 8 \mathrm{H}_{2} \mathrm{O} \\
\mathrm{Al}(\mathrm{OH})_{3} \\
\mathrm{Eu}(\mathrm{OH})_{3} \\
\mathrm{ScOOH} \\
\mathrm{Sc}(\mathrm{OH})_{3} \\
\mathrm{Sc} \mathrm{O}_{3} \\
\mathrm{Ca}(\mathrm{OH})_{2} \\
\mathrm{Fe}(\mathrm{SO})_{3} \\
\mathrm{CER}(\text { as resin })\end{array}$ \\
\hline
\end{tabular}

Some additions of the chemical system were needed: The cationic resin (CER) was modelled as $\left(\mathrm{C}_{8} \mathrm{H}_{8} \mathrm{SO}_{3}\right)_{2}\left(\mathrm{NH}_{4}\right)_{2}$ and respective resin after ion exchange was modelled e.g. $\left(\mathrm{C}_{8} \mathrm{H}_{8} \mathrm{SO}_{3}\right)_{2} \mathrm{Ca}$ or $\left(\mathrm{C}_{8} \mathrm{H}_{8} \mathrm{SO}_{3}\right)_{3} \mathrm{La}$. The resin was applied during adsorption-desorption process and omitted for the precipitation modelling. As Pitzer parameters are not available for the majority of rare earth element ions respective parameters of known ions were applied, e.g. Pitzer parameters of $\mathrm{Fe}^{3+}$ were used for modelling $\mathrm{La}^{3+}$ ion.

Adsorption-desorption model is based on the experimental measurements. Precipitation model is parametrized based on the chemical feeds and $\mathrm{pH}$ values of the process. The model itself is able to predict the $\mathrm{Fe}-\mathrm{Al}-\mathrm{Sc}$ precipitation and recovering $\mathrm{La}$ and $\mathrm{Eu}$ at the final stage.

\section{Conclusions}

In a series of experiments on the extraction of REE from uranium in-situ-leaching solutions concentrates were obtained as REE carbonates containing 50-55\% (98-99\% of oxides). The content of all impurities was not more than $1 \%$. According to the results of the first experiment was prepared concentrate containing $30-40 \%$ Sc. The average specific activity in the concentrates was 1000-1500 $\mathrm{Bq} / \mathrm{kg}$. From the experimental procedure the following conclusions could be drawn.

1. REE in sulfuric acid solutions is present in the form of positively charged or neutral complexes, which, obviously, will play a major role in the processes of sorption and extraction. With decreasing $\mathrm{pH}$ stability of negatively charged complexes increases.

2. The selectivity of REE and associated elements can be achieved using sulfonated cation exchanger with a DVB content of $>12 \%$ at $\mathrm{pH}=1.5-2.0$.

3. Functional groups of strongly acidic cation exchangers strongly affected REM ions in a wide range of concentrations of sulfuric acid. Therefore, there is the possibility of separating the 
sulfuric acid adsorbed components according to their distribution coefficients. We investigated the pre-rinsing sulfonic resins with sulfuric acid. The optimum concentration of sulfuric acid in the washing solution is $75 \mathrm{~g} / \mathrm{dm}^{3}$. Thus, it becomes possible to wash away iron ions to $38 \%$ of aluminum ion at $58 \%$ of the calcium ion by $35 \%$, of the thorium ion at $14 \%$ of the uranium ions to $75 \%$. The optimum load on the column during the washing is 5 volumes of solution to 1 volume of the cation exchanger per hour.

4. Desorption of REEs can be carried out with ammonium sulfate solution. When depositing REE from the eluate a concentrate with an average grade of REE at $32.8 \%$ was obtained.

5. The greatest capacity of scandium in the investigated conditions was achieved with a multifunctional cation exchange resin containing sulfonic and phosphonic functional groups. An ion exchanger of this type is under development by the Russian company AXION. Presented test cation exchanger ECO-10M exceeds the capacitive characteristics of known commercial resins.

6. Phosphonic functional groups of the cation exchanger ECO-10M binds scandium ions in a wide range of concentrations of sulfuric acid, enabling separation of adsorbed components according to their distribution coefficients. The optimum concentration of sulfuric acid to the washing solution is $150 \mathrm{~g} / \mathrm{dm}^{3}$. Thus, it becomes possible to wash away iron ions to $92 \%$ of aluminum ion at $50 \%$ of the calcium ion by $21 \%$, of the thorium ion at $14 \%$ and of the uranium ions to $7.6 \%$. The optimum load is $5: 1$ solution:cation exchanger volume per hour.

7. The highest efficiency in the stripping scandium from ECO-10M appeared in sodium carbonate solution with a concentration of $200 \mathrm{~g} / \mathrm{dm}^{3}$. Desorption of scandium after washing the cation exchanger ECO-10M sulfate solution should be carried out in a static mode with constant stirring . The optimum ratio of the desorption solution: cation exchanger $=5$.

8. The specific activity of the primary REE concentrates and scandium was $(5.8 \pm 0.9) \cdot 106 \mathrm{~Bq} /$ $\mathrm{kg}(1.8 \pm 0.25) \cdot 108 \mathrm{~Bq} / \mathrm{kg}$, respectively. Specific activity primary concentrates do not satisfy the technical requirements 95.148-77 TU 1767-009-00545484-2000 (up to $103 \mathrm{~Bq} / \mathrm{kg}$ ) and will require further purification of radionuclides purification factor of at least $6 \cdot 103$ in the case of lanthanide concentrate and $2 \cdot 105$ in the case of concentrate scandium. Radiochemical treatment at 5000-10000 times the level that produces a concentrate $\mathrm{Sc}$ with a specific activity of not more than $105 \mathrm{~Bq} / \mathrm{kg}$ - meets MZUA levels in the workplace. Further decontamination will be carried out in the preparation of Sc oxides.

\section{References}

1. L. N. Komissarova et al. Разделение близких по свойствам редких металлов. Металлургиздат, 130 (1962)

2. К. А. M. Bolshakova, (ed.) Химия и технология редких и рассеянных элементов. Vol. 2, Высшая школа 360 (1976)

3. R. A. Abdulvaliev, L. P. Ni, V. L. Reizman, Райзман Получение скандия из бокситового сырья. Almaty, Гылым 196 (1992)

4. E. I. Kazantsev, A. N. Denisov, Russ. J. Inorg. Chem., 8(9), 2189 (1963)

5. E. I. Kazantsev, N. V. Sapogov, Russ. J. Inorg. Chem., 39(8), 1973 (1966)

6. E. I. Kazantsev, N. V. Sapogov, Proc. of Higher Schools, Non-Ferrous Metallurgy, 6,103 (1966)

7. S. F. Lincoln, Inorg. Bioinorg. Mech. 4, 217 (1986)

8. G.W. Nestor, J. E. Enderby, Adv. Inorg. Chem. 34, 195 (1989)

9. L. N. Komissarova, Редкоземельные металлы. Сб. статей. М. Химия, 19, 256 (1957)

10. Y. Р. Kudryavsky, et al., Известия ВУЗов. Химия и химическая технология. 49, 1524 (1975)

11. M. P. Noskova et al., Russ. J. Phys. Chem. A. 57(3), 707 (1983)

12. VTT, Balas, balas.vtt.fi (2007)

13. P. Koukkari, K. Penttilä, K. Hack, S. Petersen, CHEMSHEET - An Efficient Worksheet Tool for Thermodynamic Process Simulation, in: Bréchet, Y. (Ed.), (Wiley-VCH, Weinheim, 2005) 